\title{
A New Interpretation of Contributions Presented at the Solvay Conference 1911. Can We Falsify the "Geocentric" Foundations of Quantum Mechanics in the Solar System?
}

\author{
Jiří Stávek
}

\begin{abstract}
We have studied the contributions and presentations published in the Proceedings of the Solvay Conference 1911. Based on the lecture of Ernest Solvay on the "gravitomatérialitique" we can distinguish two features of the Earth's gravitational field - 1. "gravité réelle" described by the Newton's gravitational law and 2. "gravité potentielle" acting as an agent of the self-organization on quantum particles and creating structures described by the Planck constant hEArTh. From the discussions followed after the presentations of Walther Nernst and Albert Einstein we interpreted the Nernst- Lindemann Formula for the specific heat of solids using the comment of Heike Kamerlingh Onnes (the discoverer of the superconductivity) as two transverse and one longitudinal oscillations of phonon in the surroundings at temperature $T$. In order to falsify this "geocentric" model of foundations of quantum mechanics in the spirit of Karl

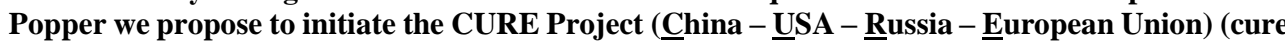
= to solve a problem) in order to build quantum laboratories on different orbits around the Earth, on the surface of the Moon and Mars, and in the Lagrange points of the system the Earth - Moon and the Earth - Sun to get new experimental data for the specific heat of solids, the critical temperatures of superconductors, chemical and physical self-organized reactions (Liesegang rings, Belousov- Zhabotinsky waves, chemical clocks, Bose-Einstein condensates, de Broglie waves, etc.). There is space enough for all participants on this CURE Project to collect new valuable data describing this "hidden variable" presented by Ernest Solvay in his forgotten lecture in 1911.
\end{abstract}

Keywords - The Solvay conference 1911, Solvay's lecture, Nernst's lecture, Einstein's lecture, "geocentric" foundations of quantum mechanics, falsification of this "geocentric" model, the CURE Project.

\section{INTRODUCTION}

All historians of modern physics highlighted the decisive significance of the first Solvay conference in 1911 and stressed the start of a collective awareness for the understanding of quantum theory. The meeting took place in the hotel Métropole in Brussels from October 29 to November 3, 1911. The first lecture was given by Ernest Solvay [1] followed by valuable presentations and discussions of invited participants. The proceedings were published both in the French language [2] in 1912 and in the German language [3] in 1914 with addendum with new theories on the specific heat of solids. However, the Ernest Solvay's paper was not published and not discussed at that Conference. Later no historians of physics gave their attention to the Solvay's model.

This special event would become a milestone in the history of physics where the foundations of quantum mechanics were openly discussed among top physicists of that epoch and still attracts the attention of new generations of scholars in this field [4]-[14].

One of the main topics of this Conference was focused on the specific heat of solids. This subject was presented by Walther Nernst and Albert Einstein and followed by very fruitful discussions. We know from the literature [15]-[22] that Albert Einstein during his stay in Prague (April 1911 - July 1912) worked mainly on two topics: the specific heat of solids and the gravitational theory. Can we fuse these two Einstein's Prague topics into one concept? 


\section{HOW TO DECIPHER THE MYSTERIOUS CONTRIBUTION OF ERNEST SOLVAY?}

Ernest Solvay opened the Conference with his inaugural speech and outlined his contribution "Sur 1'Etablissement des Principes fondamentaux de la Gravito-Matérialitique" [1]. Every participant of this Conference received a reprint of this Solvay presentation. However, this contribution is very mysterious and therefore, it was neither discussed at the Conference nor published in the Conference Proceedings. Later no historians of physics tried to analyze the Solvay's paper with its length of 109 pages.

We might discover the key how to unlock the Solvay's paper on the page 65 of his Contribution. Solvay introduced two features of the Earth's gravitational field. The first visible property of the Earth's gravitational field Solvay termed as "gravité réelle" - this is the very well-known Newtonian gravitational law. The second invisible property of the Earth's gravitational field termed as "gravité potentielle" might be the missing hidden variable behind those self-organizing processes among quantum particles.

We assume that the effect of the Earth's gravitational field leads to the "geocentric" interpretation of quantum mechanics. In order to falsify this scenario in the spirit of Karl Popper [23] we have to collect new experimental data for self-organized processes under various combinations of gravitational fields - Earth, Moon, Mars, and Sun.

\section{SPECIFIC HEAT OF SOLIDS AT THE SOLVAY CONFERENCE 1911}

Albert Einstein and Walther Nernst presented their formula on the specific heat of solids. Albert Einstein already in 1907 contributed to the significance of the newly born quantum mechanics with his Formula [24]-[25]:

$$
C_{V}=3 R\left[\frac{x^{2} e^{x}}{\left(e^{x}-1\right)^{2}}\right] \text { for } x=\frac{h v_{E}}{k T}
$$

where $\mathrm{C}_{\mathrm{V}}$ is the specific molar heat, $\mathrm{R}$ is the gas constant, $\mathrm{h}$ is the Planck constant, $v_{\mathrm{E}}$ is the Einstein's monochromatic oscillation, $\mathrm{k}$ is the Boltzmann constant and $\mathrm{T}$ is temperature of the surroundings. Albert Einstein made a breakthrough to the description of the specific heats of solid but was not satisfied with the monochromatic oscillation $v_{\mathrm{E}}$ of the solid.

Walther Nernst and Frederik Lindemann presented their Formula [26]-[28] that matched better the experimental data at lower temperatures. This Nernst-Lindemann formula was discussed in details at the Solvay Conference 1911 because its physical interpretation was not clear: Equation 2:

$$
C_{V}=\frac{3}{2} R\left[\frac{x^{2} e^{x}}{\left(e^{x}-1\right)^{2}}+\frac{\left(\frac{x}{2}\right)^{2} e^{x / 2}}{\left(e^{x / 2}-1\right)^{2}}\right]
$$

where $\mathrm{x}=\left(\mathrm{h} v_{\mathrm{NL}}\right) /(\mathrm{kT})$ with the two characteristic Nernst-Lindemann oscillations: $v_{\mathrm{NL}}$ and $v_{\mathrm{NL} / 2}$.

Several remarks from the discussion after Walther Nernst presentation at the Solvay Conference 1911 on the meaning of the Nernst - Lindemann Formula.

Walther Nernst: "We assume that the thermal energy is composed from kinetic energy and potential energy."

Albert Einstein: "The formula of Nernst and Lindemann is undoubtedly a great progress, but I am of the opinion that it should not be considered as anything other than an empirical formula."

Heike Kamerlingh Onnes (discoverer of superconductivity in 1911): "We could suppose that two of these oscillations are of the nature of transverse vibrations and the third of longitudinal vibrations."

Heike Kamerlingh Onnes in his lecture on the discovery of the superconductivity mentioned that NernstLindemann Formula might be applicable to explain the decreasing resistance of metals and in the discussion, he noticed on the mechanism of superconductivity [29]: "It is also possible that the modification consists mainly in the change of the period of the vibrations of which I have just spoken."

\section{SOME LATER COMMENTS ON THE NERNST-LiNDEMANN FORMULA}

There were several remarks to the Nernst-Lindemann Formula after the Solvay Conference 1911.

Arnold Eucken in 1914 [3] in the Addendum of the German translation of the Solvay Conference 1911 added: "Even today, quantum theory remains at its core an unsolved mystery, and views are still thoroughly 
divided as to where a key can be found." Arnold Eucken on the Nernst-Lindemann Formula: "As surprising as the achievements of this formula were, it could not yet be seen as a definitive solution."

Peter Debye in 1912 on the Nernst-Lindemann Formula [30]: "The introduction of this second oscillation number corresponds to the practical need for a better formula than Einstein's, but it was not possible to find any valid reason for this value $v / 2$."

Otto Sackur in 1912 [31]: "Nernst-Lindemann Formula has not yet found a theoretical interpretation."

Fritz Reiche in 1912 in [4]: "By establishing an empirical formula - which, however, must be regarded as obsolete according to the current state of research - W. Nernst and F. Lindemann succeeded in representing also the values deviating from Einstein's curve."

E.H. Griffiths and E. Griffiths in 1914 [32]: "The Nernst-Lindemann formula is empirical but appears to have been a step in the right direction."

Hermann Sieveking in 1914 [33]: "The formula of Nernst and Lindemann provides at the same time the possibility of a simple derivation of Planck's radiation formula."

O. W. Richardson in 1914 [34]: "Nernst-Lindemann formula contains only one adjustable parameter, the frequency $v$, so that the agreement with the data is quite convincing." p. 359. And "Nernst-Lindemann formula has never received a satisfactorily theoretical explanation." p. 360.

Siegfried Valentiner in 1921 [35]: "Nernst and Lindemann attempted to theoretically interpret their formula, but this was not convincing."

Fritz Reiche in 1921 [36]: "The Nernst-Lindemann formula has now only historical interest."

Frederik Lindemann in 1936 [37]: "The Nernst-Lindemann formula was a pioneer attempt to connect the specific heat of a substance with its characteristic frequencies."

Generally, the Nernst-Lindemann Formula was not later theoretically developed and the guiding principle for the evaluation of the specific heat of solids was formulated by Peter Debye in 1912 [30] and by Max Born and Theodore von Kármán [38].

Both Einstein's and Nernst-Lindemann's formulae have been discussed in later papers with the focus on the historical development of the concept of quantum specific heats, e.g., [39]-[46].

\section{MODIFICATION OF THE NERNST-LINDEMANN FORMULA INSPIRED BY SOLVAY AND KAMERLINGH ONNES}

We have modified the Nernst-Lindemann Formula based on the discussion comment of Heike Kamerlingh Onnes: "We could suppose that two of these oscillations are of the nature of transverse vibrations and the third of longitudinal vibrations.". The phonon transverse oscillation has two amplitudes per one wavelength and therefore the frequency of the transverse oscillation is $v_{\mathrm{KO}}$, while the frequency of the longitudinal oscillation is $v_{\mathrm{KO}} / 2$ :

$$
C_{V}=R\left[2 \frac{x^{2} e^{x}}{\left(e^{x}-1\right)^{2}}+\frac{\left(\frac{x}{2}\right)^{2} e^{x / 2}}{\left(e^{x / 2}-1\right)^{2}}\right]
$$

where $\mathrm{x}=\left(\mathrm{h} v_{\mathrm{KO}}\right) /(\mathrm{kT})$ with the characteristic Kamerlingh Onnes oscillation $v_{\mathrm{KO}}$.

During our literature search we have rediscovered this identical modification of the Nernst-Lindemann Formula in the paper of Sebastiano Tosto [47] in his Equation 14 and Figure 2 where the comparison with the Debye model is presented. There is no direct citation to the Nernst-Lindemann Formula, only one indirect citation via the book J. Mehra and H. Rechenberg [43] where is the Nernst-Lindemann Formula reviewed. Sebastiano Tosto's interpretation of this Formula is based on the concept of the "zero-point energy". In our present model we interpret the physical agent acting in the Equation 3 as the Solvay's "gravité potentielle" that might be the missing "hidden variable" behind self-organizing processes among quantum particles on the surface of the Earth.

This Solvay's model can be experimentally tested during this decade because we have now a possibility to build quantum laboratories at some special locations in the Solar system where are different intensities and combinations of gravitational fields of the Earth, Moon, Sun, and Mars.

\section{QUANTUM PHYSICS AND QUANTUM CHEMISTRY IN SPACE}

The dream of Max Planck [48] in 1900 was to define natural units “...which, independent of special bodies or substances, necessarily retain their meaning for all times and for all, also extraterrestrial and extra- 
human cultures, and which can therefore be called natural units of measurements."

This was the main reason why the International System of Units (the SI) replaced the definition of the

kilogram based on the material artefact to the definition based on the Planck constant, e.g. [49]-[51].

One of the conclusions of the concept presented in this contribution is following: we might replace "one special body" (the International Prototype of Kilogram - IPK) by "another special body" representing by the Earth and Her gravitational field. In our epoch we should collect experimental data from Space around the Earth to investigate our natural units (e.g., Planck constant, Boltzmann constant) and other properties of quantum particles how they are dependent on the intensity of gravitational field and combinations of several gravitational fields.

We know from the literature that there exist a lot of initiatives to study quantum physical processes in Space, e.g. [52]-[55]. In several cases, it is very difficult to realize some of those processes as e.g., the interference of the Bose-Einstein Condensates because of the complexity of the needed instruments, the double-slit experiment with individual particles, and the entanglement when both partners are located in Space.

In order to verify the hypothesis in this contribution based on the influence of gravitational fields on the formation of structures among quantum particles we propose to study more easier experimental projects: measurement of the specific heat of solids, the critical temperature of superconductors, the chemical and biological periodic patterns - Liesegang rings (e.g., [56]-[59]), Belousov-Zhabotinsky waves (e.g., [60][62]), chemical clocks (e.g., [63]-[66]).

\section{CONCLUSION}

In order to test the "geocentric" foundations of quantum mechanics it will be necessary to organize the Planet Earth Network to build and place quantum laboratories in some special orbits around the Earth, Moon, Mars, the Lagrange points belonging to those objects and to formulate a matrix for those experiments. The "nucleation particle" for these activities might be the joint effort of China, USA, Russia, and European Union as The CURE Project (cure = to solve a problem) around which the "Planetary crystal" might grow. There is space enough for all participants on this CURE Project.

\section{ACKNOWLEDGMENT}

We were supported by the contract number $0110 / 2020$.

\section{REFERENCES}

[1] Solvay E. Sur l'etablissement des principes fondamentaux de la gravito-matérialitique. Imprimente-Lithographie G. Bothy, Bruxelles, 1911, page 65.

[2] Langevin P, Broglie M. La théorie de rayonnement et les quanta. Rapports et discussions de la réunion tenue à Bruxelles, du 30 octobre au 3 novembre 1911. Sous les auspices de M.E. Solvay. Paris, Gauthier-Villars, 1912.

[3] Eucken A. Die Theorie der Strahlung und der Quanten. Verhandlungen auf einer von E. Solvay einberufenen Zusammenkunft (30. Oktober bis 3. November 1911), mit einem Anhang über die Entwicklung der Quantentheorie vom Herbst 1911 bis Sommer 1913. Knapp, Halle a.S. 1914

[4] Reiche F. Die Quantentheorie. Naturwissenschaften. 1913; 1: 549-552 and 568-571.

[5] de Broglie M. Les premiers congrès de physique Solvay et l'orientation de la physique depuis 1911, Cahiers de la collection Sciences d'Aujourd'hui, dirigés par André George, Paris, Albin Michel, 1951.

[6] Mehra J. The Solvay conferences on physics: aspects of the development of physics since 1911. D. Reichel, Dordrecht, Holland, 1975.

[7] Kormos Barkan D. The witches'sabbath: the first international Solvay congress in physics. Science in Context. 1993; 6: 59-82.

[8] Marage P, Wallenborn G. (Eds.), The Solvay Councils and the Birth of Modern Physics. Birkhäuser Verlag, 1999.

[9] Galison P. Solvay Redivivus. In: The Quantum Structure of Space and Time, Proceedings of the $23^{\text {rd }}$ Solvay Conference on Physics, Brussels, Belgium, 1-3 December, 2005, Eds. D. Gross, M. Henneaux, and A. Servin, World Scientific, New Jersey, 2007.

[10] Straumann N. On the first Solvay Congress in 1911. The European Physical Journal H. 2011; 36: 379-399.

[11] Lambert F, Berends |F, Eckert M. The early Solvay councils and the advent of the quantum era. The European Physical Journal Special Topics. 2015; 224: 2011-2021.

[12] Lambert FJ, Einstein's witches' sabbath in Brussels: The legend and facts. The European Physical Journal Special Topics, 2015; 224: 2023-2040.

[13] Foucart S. Au Métropole un <sabbath de sorcières>. In le Monde, 31 July, 2015.

[14] Lambert F, Berends F, Einstein's witches' sabbath and the early Solvay councils: the untold story. Kindle Edition, EDP Sciences November 18, 2021.

[15] Frank P, Einstein. Sein Leben und seine Zeit. Vieweg, 1949.

[16] Illy J, Einstein in Prague. ISIS. 1979; 70: 76-84.

[17] Bičák J, Einstein's Days and Works in Prague. In Physics and Prague, J. Fanta and J. Niederle (Eds.), The Union of Czechoslovak Mathematicians and Physicists, Prague, 1984.

[18] Einstein A. The Collected Papers of Albert Einstein. Volume 3: The Swiss Years: Writings, 1909-1911, Eds.: R. Schulmann, A.J. Kox, and J. Renn, 1994.

[19] Einstein A. The Collected Papers of Albert Einstein. Volume 4: The Swiss Years: Writings, 1912-1914, Eds.: R. Schulmann, A.J. Kox, and J. Renn, 1996. 
[20] Einstein A. The Collected Papers of Albert Einstein. Volume 5: The Swiss Years: Correspondence, 1902-1914, Eds.: R. Schulmann, and A.J. Kox, 1994.

[21] Gordin MD. Einstein in Bohemia. Princeton University Press, 2020. ISBN-10: 0691177376.

[22] Gutfreund H., Otto Stern - with Einstein in Prague and Zürich,' In: Friedrich B., Schmidt-Böcking H. (Eds.) Molecular Beams in Physics and Chemistry, Chapter 6, Springer, 2021.

[23] Popper K. Quantum Theory and the Schism in Physics: From the Postscript to the Logic of Scientific Discovery. Routledge, ISBN-10: 0415091128, 1989.

[24] Einstein A. Planck's theory of radiation and the theory of specific heat. Annalen der Physik, 1907; 22:180-190.

[25] Einstein A. Elementary observations on thermal molecular motion in solids and note added in proof. Annalen der Physik. 1911; 35:679-694.

[26] Nernst W, Lindemann FA. Untersuchung über die spezifische Wärme bei tiefen Temperaturen. V. Sitzungsberichte der Berl. Akad. der Wiss., 1911; 492-501.

[27] Nernst W, Lindemann FA. Spezifische Wärme und Quantentheorie. Zeitschrift für Elektrochemie. 1911; 18: 817-827.

[28] Kormos Barkan D. Walther Nernst and the Transition to Modern Physical Science. Cambridge University Press, Cambridge, 1999.

[29] Kamerlingh Onnes H. "Sur les Résistances Electriques," pp. 304-312 in Reference [2].

[30] Debye P. Zur Theorie der spezifischen Wärme. Annalen der Physik. 1912; 39:789-839.

[31] Sackur O. Lehrbuch der Thermochemie und Thermodynamics. Berlin, Julius Springer, 1912.

[32] Griffiths EH, Griffiths E. The Capacity for Heat of Metals at Low Temperatures. Phil. Trans. Royal Soc. Series A, Containing Papers of a Mathematical or Physical Character. 1914; 214: 319-357.

[33] Sieveking H. Moderne Probleme der Physik. Vieweg Verlag, Braunschweig, p. 142, 1914

[34] Richardson OW. The Electron Theory of Matter. Cambridge University Press, Cambridge, 1914.

[35] Valentiner S. Anwendung der Quantenhypothese in der kinetischen Theorie der festen Körper und der Gase in elementaler Darsttellung. Vieweg Verlag, Brauschweig, 1921.

[36] Reiche F. Die Quantentheorie. Ihr Ursprung und ihre Entwicklung. Springer Verlag, Berlin, 1921.

[37] Lindemann F. Guthrie Lecture: Prof. F.A: Lindemann, F.R.S. Nature. May 16, 1936; page 809.

[38] Born M, von Kármán T. Zur Theorie der spezifischen Wärme. Physikalische Zeitschrift. 1913; 14:15-19.

[39] Nath NN. The dynamical theory of the diamond lattice. Proceedings of the Indian Academy of Sciences, Section A. 1935; 2: 143152.

[40] Klein MJ. Einstein, Specific heats, and the early quantum theory. Science, New Series, 1965; 148: 173-180.

[41] Pais A. Einstein and the quantum theory. Reviews of Modern Physics, 1979; 51:863-914.

[42] Hulin M. En attendant Debye... Eur. J. Phys., 1980; 1: 222-224.

[43] Mehra J, Rechenberg H. The quantum theory of Planck, Einstein, Bohr, and Sommerfeld: Its foundation and the rise of its difficulties 1900-1925. In: The historical development of quantum theory, vol. 1, part 1, Springer Verlag, New York, 1982.

[44] Kox AJ. Einstein, specific heats, and residual rays: the history of a retracted paper," In: No truth except in the details, Eds.: A.J. Kox and D.M. Siegel, Kluwer Academic Publishers, 1995.

[45] Pérez E. Einstein i la calor expecífica dels sòlids: arguments per a una teoria quàntica. Revista de Física. 2007 ; 4: $34-48$.

[46] Irons FE. New method for reducing the general formula for lattice specific heat to the Einstein and Nernst-Lindemann approximations. Canadian Journal of Physics. 2011; 81: 1015-1036.

[47] Tosto S. Reappraising 1907 Einstein's Model of Specific Heat. Open Journal of Physical Chemistry. 2016; 6: 109-128, Equation 14, Figure 2.

[48] Planck M. Ueber irreversible Strahlungsvorgänge. Annalen der Physik. 1900; 17: 273-301.

[49] Mills IM., Mohr PJ, Quinn TJ, Taylor BN, and Williams ER. Redefinition of the kilogram: a decision whose time has come. Metrologia. 2005; 42: 71-80.

[50] Schlamminger S. Redefining the Kilogram and Other SI Units. Physics World Discovery, 2018; 1-25.

[51] Ketterle W, Jamison AO. An atomic physics perspective on the kilogram's new definitions. Physics Today, 2020; 73: 32-38.

[52] Liao SK. et al. Satellite-to-ground quantum key distribution. Nature. 2017; 549: 43-47.

[53] Gasbarri G. et al. Testing the foundation of quantum physics in space via Interferometric and non-interferometric experiments with mesoscopic nanoparticles. Communications Physics, 2021; 4: 155-168.

[54] Lachmann MD. et al., Ultracold atom interferometry in space. Nature Communications, 2021; 12: 1317-1323.

[55] Belenchia A. et al. Quantum physics in space," Arxiv: 2108.01435v1., Review with 124 pages, 2021.

[56] Mikhalev PF, Shemyakin FM. The wave theory of periodic reactions. V. An investigation of periodic reactions by the method of physical-chemical analysis. J. Gen. Chem., 1934; 4:1117.

[57] Stávek J, Šípek M. Interpretation of periodic precipitation pattern formation by the concept of quantum mechanics. Crystal Research and Technology, 1995; 30:1033-1049.

[58] García-Ruiz JM, Rondón D, Garcia-Romero A, Otálora F. Role of gravity in the formation of Liesegang patterns,” J. Phys. Chem., 1996; 100: 8854-8860.

[59] Mareš JJ, Stávek J, Šesták J. Quantum aspects of self-organized periodic chemical reactions. J. Chem. Phys., 2004; 121: 14991503.

[60] Zhabotinsky AM. Belousov-Zhabotinsky reaction. Scholarpedia, 2007; 2: 1434.

[61] Flesselles JM, Belmonte A, Gáspár V. Dispersion relation for waves in the Belousov-Zhabotinsky reaction. J. Chem. Soc., Faraday Trans., 1998; 94 951-855.

[62] Klink O, W. Hanke W, Gerberhagen E, de Lima VMF. Influence of heavy water on waves and oscillations in the BelousovZhabotinsky reaction. In: Ed. A. Petrin, Wave propagation in materials for modern applications, Ch. 21, pp. 409-418, 2010.

[63] Kapral R, Showalter K. Eds. Chemical waves and patterns. Vol. 10, Springer Science \& Business Media, 2012.

[64] Johnson-Buck A, Shih WM. Single-molecule clocks controlled by serial chemical reactions. Nano Lett., 2017 ; $17:$ 7940-7944.

[65] Gentili PL, Micheau JC. Light and chemical oscillations: review and perspective. Journal of Photochemistry and Photobiology C: Photochemistry Reviews, 2020; 43:100321.

[66] Osypova A, Dübner M, Panzarasa G. Oscillating reactions meet polymers at interfaces. Materials, 2020; $13: 13132957$. 